\title{
Exclusion mapping of the hereditary dentatorubropallidoluysian atrophy gene from the Huntington's disease locus
}

Ikuko Kondo, Hitoshi Ohta, Mitsuyasu Yazaki, Joh-E Ikeda, James F Gusella, Ichiro Kanazawa

\begin{abstract}
Hereditary dentatorubropallidoluysian atrophy (DRPLA) is an autosomal dominant neurodegenerative disorder. Clinical and genetic findings in hereditary DRPLA are very similar to those of Huntington's disease (HD). However, it can be differentiated from HD by the pathological findings of dentatorubral and pallidoluysian atrophies and by a lack of prominent atrophy of the striatum at necropsy. The hereditary DRPLA gene has not been localised and the possibility that the two disease loci are allelic has been suggested.

We have searched for linkage between the locus for hereditary DRPLA and D4S10 using the G8 probe, which is a genetic marker linked to HD. In four families, there were negative scores at all recombination fractions and the lod score was
\end{abstract}

Department of Human Genetics, Institute of Basic Medical Sciences, University of Tsukuba, Ibaraki 305, Japan.

I Kondo

Department of Psychiatry, Kohchi Medical School, Kohchi 781-51, Japan.

H Ohta

Department of Psychiatry, School of Medicine, University of Yamagata, Yamagata 990-23, Japan.

M Yazaki

National Institute of Agrobiological Resources, Ibaraki 305, Japan.

J E Ikeda

Neurogenetics Laboratory, Massachusetts General Hospital, Boston 02114, USA.

J F Gusella

Department of Neurology, Institute of Clinical Medicine, University of Tsukuba, Ibaraki 305, Japan.

I Kanazawa

Correspondence to Dr Kondo, Department of Ecology and Genetics, School of Health Sciences, Faculty of Medicine, University of The Ryukyus, Okinawa 903-01, Japan.

Received for publication 25 April 1989.

Revised version accepted for publication 10 July 1989.
$-2 \cdot 215$ at recombination fraction $\theta=0 \cdot 15$. These data indicate that the locus for hereditary DRPLA is not closely linked to D4S10 and that hereditary DRPLA is a distinct disease from HD.

It is not unusual in neurodegenerative disorders for the disease processes to involve two or more systems in the central nervous system, for example, cerebellar and nigrostriatal systems in olivopontocerebellar atrophy or cerebellar and autonomic systems in ShyDrager syndrome. However, the involvement of the dentatorubral and the pallidoluysian systems in the same patient is a rare combination. In $1958 \mathrm{Smith}$ et $a l^{1}$ described such a case under the title of 'Unusual form of cerebellar ataxia. Combined dentato-rubral and pallido-Luysian degeneration'. Although several sporadic cases similar to that of Smith $e t \mathrm{al}^{1}$ have been reported, ${ }^{2-4}$ this particular disease, now named dentatorubropallidoluysian atrophy (DRPLA), seems to be extremely rare in western countries. However, during the last 10 years, many hereditary cases of DRPLA have been reported in Japan. . $9^{5}$

Clinical signs and symptoms vary greatly from case to case, ${ }^{5}$ but can be summarised as follows. (1) Patients under the age of 20 usually show clinical features of myoclonic epilepsy; (2) patients between the ages of 20 and 40 mostly show cerebellar ataxia and epilepsy; and (3) patients over the age of 40 usually show choreic involuntary movements and dementia with mild cerebellar ataxia. With regard to (3), it is sometimes difficult to differentiate a patient with DRPLA from Huntington's disease (HD) based on clinical features. ${ }^{79}$ Although it is possible to differentiate DRPLA from HD through the pathological features of the degeneration both in the dentatorubral and the pallidoluysian systems and the lack of the prominent degeneration in the striatum, several cases of DRPLA have been reported under the 'pathological diagnosis' of HD. This may have been because of the theory that DRPLA is a variation of HD. In addition, DRPLA is similar to HD in terms of inheritance; most cases of DRPLA reported in Japan showed autosomal dominant inheritance, ${ }^{5}$ which creates further difficulty in differentiating the two. 
Therefore, it is possible to speculate that hereditary DRPLA and HD are actually allelic at the same disease locus, which is similar to the relationship between Duchenne and Becker muscular dystrophies.

To confirm that hereditary DRPLA is a distinct neurodegenerative disorder from $\mathrm{HD}$, we have studied linkage between the locus for hereditary DRPLA and D4S10, which is linked to the HD gene, using the G8 probe. ${ }^{10}$

\section{Subjects and methods}

SUBJECTS

The pedigrees of the families studied are shown in fig 1 together with the age at which the DNA polymorphisms were analysed. Hereditary DRPLA was diagnosed according to the neuropathological findings in affected subjects in the same families at necropsy. Affected patients studied had various clinical symptoms including ataxia, epilepsy, myoclonus, dementia, and involuntary movements.

Peripheral B lymphocytes were transformed using
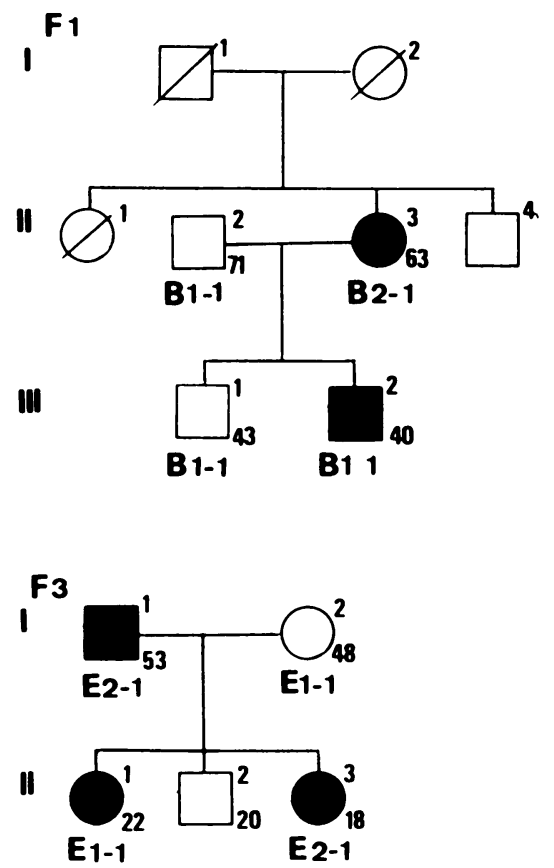

Epstein-Barr virus from families with hereditary DRPLA and unrelated healthy Japanese controls, and DNA was extracted from established lymphoblasts using the method of Kunkel et al. ${ }^{11}$ Restriction $\stackrel{\mathbb{Q}}{\stackrel{9}{ }}$ endonuclease digestion (HindIII, BglI, and EcoRI) was performed under conditions recommended by the $\stackrel{\sim}{\rightarrow}$ manufacturer (Takara Shuzo Co Ltd, Kyoto, Japan). Digested DNA samples were electrophoresed on a $0.7 \%$ agarose gel, denatured, and transferred to nitrocellulose membranes in $6 \times$ SSC. $^{12}$ After pre- $\stackrel{\mathbb{D}}{\circ}$ hybridisation, the membranes were hybridised with ${ }^{32} \mathrm{P}$ labelled pKO82 and pKO83 probes, subcloned from probe G8, under conditions described by Gusella et al. ${ }^{10}$ Autoradiographs were developed at $-70^{\circ} \mathrm{C}$ using Kodak Exomat films and super-rapid intensifying screens for four days.

\section{LINKAGE ANALYSIS}

The analysis of genetic linkage between the locus for hereditary DRPLA and genotypes of the G8 probe were performed using the method of Morton. ${ }^{13}$
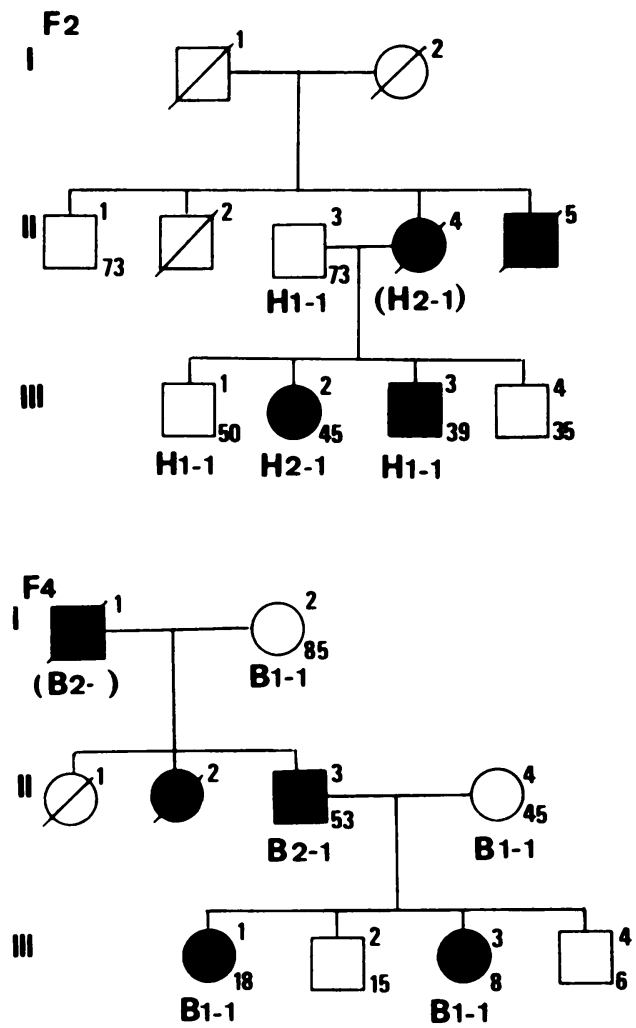

Figure 1 Family pedigrees showing phenotypes, genotypes of DNA polymorphisms, and age at study. $H, B$, and $E: H i n d I I I, B g l I$, and EcoRI polymorphisms. Parentheses indicate genotypes of DNA polymorphisms not tested, but deduced from typing of other family members. 
Table 1 Polymorphisms at the D4S10 locus in 50 Japanese.

\begin{tabular}{llccccc}
\hline & & \multicolumn{2}{c}{ Size of fragment $(\mathrm{kb})$} & & \multicolumn{2}{c}{ Allele frequency } \\
\cline { 3 - 4 } Probe & Enzyme & Allele 1 & Allele 2 & & Allele 1 & Allele 2 \\
\hline pKO82 & HindIII & $3 \cdot 7$ & $4 \cdot 9$ & & 0.867 & 0.133 \\
pKO82 & BgII & $2 \cdot 6$ & $3 \cdot 7$ & & 0.083 & 0.917 \\
pKO83 & EcoRI & $9 \cdot 0$ & 14.0 & 0.510 & $0 \cdot 490$ \\
\hline
\end{tabular}

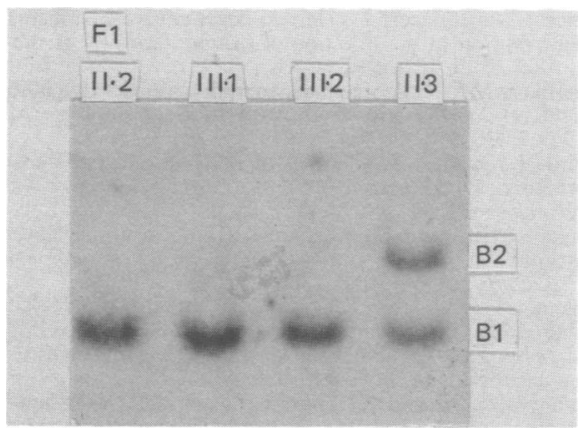

Figure 2 Southern blot of probe G8 ( $p$ KO82) with BglI digested genomic DNA from family 1.

\section{Results \\ ALLELIC FREQUENCIES}

Polymorphisms at the D4S10 locus in a Japanese population sample are summarised in table 1 . Allelic frequencies of haplotypes studied in 50 unrelated, healthy Japanese were very similar to those in Caucasians. ${ }^{10}$

\section{GENETIC LINKAGE DATA}

The pedigrees and RFLP phenotypes at the D4S10 locus in four informative families are illustrated in fig 1. We analysed the lod scores in affected subjects and in unaffected relatives, including only those over the age of $\mathbf{4 0}$ years and older than the affected offspring, because the mean age at onset of the disease is 31.9 years (range 6 to 69 ). ${ }^{5}$
In family 1 , the affected mother (II-3) typed as $B g I I$ 2-1 (B 2-1) and her two offspring (III $\cdot 1$ and III $\cdot 2$ ) typed as B 1-1 (figs 1 and 2). However, only III $\cdot 2$, was affected; III 11 was older at 43 years and was healthy. Therefore, there was one recombinant between the D4S10 locus and the disease locus in this family.

In family 2 , two affected offspring (III $\cdot 2$ and III $\cdot 3$ ) had different HindIII haplotypes at the D4S10 locus and an unaffected brother (III·1) typed as HindIII 1-1 (H 1-1) (fig 1). Their unaffected father (II-3) typed as $\mathrm{H} \mathrm{1-1}$. Therefore, allele 2 of the HindIII RFLP must be derived from the affected mother (II-4), who could not be studied. Affected offspring III $\cdot 3$ must be a recombinant.

In family 3, the affected father $(\mathrm{I} \cdot 1)$ typed as $E c o$ RI 2-1 (E 2-1) and two affected daughters (II $\cdot 1$ and II $\cdot 2$ ) typed as E $1-1$ and E $2-1$, respectively (fig 1 ).

In family 4 , the affected proband (II-3) and his mother $(I \cdot 2)$ typed as B 2-1 and B 1-1, respectively. In the third generation of this family, the affected daughters (III 1 and III $\cdot 3$ ) typed as B $1-1$ (fig 1$)$. The affected father, typed as B 2-1 (II-3), must have inherited the B 2 from his affected father $(\mathbf{I} \cdot 1)$ who was not studied. Since the predicted phase would be the DRPLA gene on the chromosome containing the B 2 allele at the D4S10 locus in this family, two affected offspring (III· 1 and III· 3 ) were likely to be recombinants between the loci.

The lod scores obtained for each value of $\theta$ in individual families are shown in table 2 . The combined lod score was $-2 \cdot 281$ at recombination fraction $\theta=0.125$ and lod scores were negative at all recombination fractions.

Table 2 Lod scores for linkage between hereditary DRPLA and D4S10.

\begin{tabular}{|c|c|c|c|c|c|c|c|c|c|}
\hline \multirow[t]{2}{*}{ Family } & \multirow{2}{*}{$\begin{array}{l}\text { No of } \\
\text { NR:R }\end{array}$} & \multicolumn{8}{|c|}{ Recombination fractions } \\
\hline & & 0.00 & 0.01 & 0.05 & $0 \cdot 10$ & $0 \cdot 125$ & $0 \cdot 15$ & $0 \cdot 175$ & $0 \cdot 20$ \\
\hline $\begin{array}{l}1 \\
2 \\
3 \\
4\end{array}$ & $\begin{array}{l}1: 1 \\
2: 1 \\
1: 1 \\
0: 2\end{array}$ & $\begin{array}{l}-\infty \\
-\infty \\
-\infty \\
-\infty\end{array}$ & $\begin{array}{l}-1 \cdot 402 \\
-1 \cdot 402 \\
-1 \cdot 402 \\
-3 \cdot 398\end{array}$ & $\begin{array}{l}-0.721 \\
-0.721 \\
-0.721 \\
-2.000\end{array}$ & $\begin{array}{l}-0.444 \\
-0.444 \\
-0.444 \\
-1.398\end{array}$ & $\begin{array}{l}-0.359 \\
-0.359 \\
-0.359 \\
-1.204\end{array}$ & $\begin{array}{l}-0.292 \\
-0.292 \\
-0.292 \\
-1.046\end{array}$ & $\begin{array}{l}-0.238 \\
-0.238 \\
-0.238 \\
-0.912\end{array}$ & $\begin{array}{l}-0.194 \\
-0.194 \\
-0.194 \\
-0.796\end{array}$ \\
\hline Total & $4: 6$ & $-\infty$ & $-7 \cdot 604$ & $-4 \cdot 163$ & $-2 \cdot 729$ & $-2 \cdot 281$ & -1.923 & $-1 \cdot 626$ & $-1 \cdot 378$ \\
\hline
\end{tabular}

$\mathrm{NR}=$ non-recombinant, $\mathrm{R}=$ recombinant. 


\section{Discussion}

In 1983, Gusella et $a l^{10}$ assigned the locus for HD to the short arm of chromosome 4 using DNA probe G8 (D4S10). No evidence of heterogeneity was observed among different ethnic groups, and the combined maximum lod score was 87.69 at a recombination fraction of $4 \mathrm{cM} .{ }^{14}$ In Japanese HD families, the locus for $\mathrm{HD}$ and $D 4 S 10$ have been reported to be separated by about $15 \mathrm{cM}$ (Kanazawa et al, unpublished observations). On the other hand, linkage data studied here showed that the locus for hereditary DRPLA was excluded from the vicinity of D4S 10 at the recombination fraction $\theta=0.125$ and the lod score was -1.923 at the recombination fraction $\theta=0.15$ (table 2). Based on the loci, these data indicate that hereditary DRPLA and HD are distinct. Therefore, in pedigrees with many recombinants between $H D$ and D4S10 there is a need to reconfirm clinical and neuropathological findings, because patients with hereditary DRPLA have sometimes been diagnosed as having HD. ${ }^{79}$ In fact, there were very few families with many recombinants between $H D$ and $D 4 S 10 .{ }^{14}$

The locus for hereditary DRPLA has not been assigned. Once the gene is assigned to a specific chromosome, it will be easy to differentiate this disease from HD and other similar diseases using genetic markers linked to the disease locus. In addition, the localisation of the gene and the finding of closely linked genetic markers are important, not only to isolate the gene itself and to establish the features of the disease, but also to provide prenatal diagnosis for families who request it. Towards mapping of the locus for hereditary DRPLA, linkage analyses using highly polymorphic DNA markers on different chromosomes are under way in our laboratory.
This work was supported by Grants-in-Aid for $\stackrel{\curvearrowright}{\circledR}$ Scientific Research on Priority Areas, Ministry of $\Omega$ Education, Science, and Culture, Japan.

1 Smith JK, Conda VE, Malamud N. Unsusual form of cerebellar ataxia: combined dentato-rubral and pallido-Luysian degeneration. Neurology (Minneap) 1958;8:205-9.

2 Boström A, Spatz H. Binderarmtrophie bei idiopathisher Athetose. Arch Psychiatr Nervenkr 1928;82:271-3.

3 Titica J, van Bogaert L. Heredo-degenerative hemiballismus: a contribution to the question of primary atrophy of the corpus Luysii. Brain 1946;69:251-63.

4 Neumann MA. Combined degeneration of globus pallidus and dentate nucleus and their projections. Neurology (Minneap) 1959;9:430-8.

5 Naito H, Oyanagi S. Familial myoclonus epilepsy and choreoathetosis: hereditary dentatorubro-pallidoluysian atrophy. Neurology (Minneap) 1982;32:798-807.

6 Iizuka R, Hirayama K, Maehara K. Dentatorubro-pallidoluysian atrophy: a clinico-pathological study. $\mathcal{F}$ Neurol Neurosurg Psychiatry 1984;47:1288-98.

7 Nakano T, Iwabushi K, Yagishita S, Amano N, Akagi M, O Yamamoto Y. An autopsy case of dentato-rubropallidoluysian atrophy (DRPLA) clinically diagnosed as Huntington's chorea (in Japanese). Brain Nerve 1985;37:767-74.

8 Iwabuchi K, Amano N, Yokoi S, Nakano T, Yagishita S. Two familial cases of dentato-rubro-pallidoluysian atrophy with pseudo-Huntington's chorea (in Japanese). Clin Neurol 1985; 25:1052-60.

9 Takahashi $\mathrm{H}$, Ohama E, Naito $\mathrm{H}$, et al. Hereditary dentatorubral-pallidoluysian atrophy: clinical and pathologic variants in a family. Neurology (Minneap) 1988;38:1065-70.

10 Gusella JF, Wexler NS, Conneally PM, et al. A polymorphio DNA marker genetically linked to Huntington's disease. Nature 1983;305:234-8

11 Kunkel LH, Smith KD, Boyer SH et al. Analysis of human It chromosome-specific reiterated DNA in chromosome varianto Proc Natl Acad Sci USA 1977;74:1245-9.

12 Southern EM. Detection of specific sequences among DNA fragments separated by gel electrophoresis. F Mol Biol 1975;98: 503-17.

13 Morton NE. Sequential tests for the detection of linkage. $A m \mathcal{J}$ Hum Genet 1955;7:277-318.

14 Conneally PM, Haines JL, Tanzi RE, et al. Huntington disease: no evidence for locus heterogeneity. Genomics 1989;5:304-8. 